\title{
Directions for Improving the Tax Policy of the Republic of Crimea
}

\author{
Tamila Kadzhametova*, Asan Kerimov, and Sevilya Mustafaeva \\ Crimean Engineering and Pedagogical University the name of Fevzi Yakubov, Simferopol, 297570, \\ Russia
}

\begin{abstract}
The article analyzes the structure of the revenue and expenditure side of the budget of the Republic of Crimea in the current year, and the tax receipts at the industry level. The main criteria for the effectiveness of the regional tax policy are highlighted. The directions of the tax policy of the region, and measures to attract financial resources for investment in the economy of the region are analyzed. The authors propose the directions of improving the tax policy of the Republic of Crimea in the near future through the implementation of measures aimed at developing the regional economy and improving budgetary policy.

Key words: tax policy of the region, tax policy of the Republic of Crimea, improvement of tax policy, tax revenues of the budget, budget expenditures.
\end{abstract}

\section{Articulation of issue}

In the context of the renewal of state administration mechanisms, the search for a balance of interests of the state and the regions, the problem of developing an effective tax policy becomes especially urgent. Socio-economic transformations of the Republic of Crimea are associated with ensuring the optimal functioning and development of the tax system. The solution to these problems is associated primarily with the analysis of the directions for improving the mechanisms of state tax policy, generalization and dissemination of experience in the effective regulation of the tax policy of the regions. Taxation is a powerful financial instrument that can be effectively used to achieve certain goals. $70 \%$ of the budget revenues of the Republic of Crimea are subsidies from the federal budget. In this regard, it seems relevant to study the tax potential of the Republic of Crimea in order to improve the system of its formation and identify areas for further development.

The works of Chuzhmarova S. I. [1], Levkevich M. M., Pavlenko Yu. N. [2], Bushinskaya T. V. [3] and other scientists are devoted to the problems of state and regional tax policy. Despite the constant search for directions of state regulation of the economy, the insufficient study of the topic attaches great importance to the analysis of these problems. Issues related to the formation of the tax policy of the region require detailed study and search for ways to improve it.

\footnotetext{
*Corresponding author: tamila_b@mail.ru
} 
The purpose of the article is to analyze the structure of revenues and expenditures of the budget of the Republic of Crimea and the development of measures aimed at improving the tax policy of the region.

\section{Essential materials}

Presentation of the main material. Tax policy is an integral part of the country's socioeconomic policy, which is focused on developing a tax system that will stimulate the accumulation and rational use of the state's national wealth, and thereby ensure the socioeconomic development of society.

The specificity of the regional tax policy is its formation and implementation under the influence of the federal tax policy. In our opinion, the main criterion for the effectiveness of regional tax policy is the stability and level of socio-economic development of the region. The objective basis for the formation of a regional tax policy is the delineation of tax revenues between the federal and regional levels. The budgets of all regions of Russia need additional financial support through the provision of transfers from the federal budget.

The tax policy of the Republic of Crimea is aimed at fulfilling the national goals of the regional development, increasing the level and quality of life of the population, modernizing the infrastructure, economy and public administration, repairing the public finances of the Republic of Crimea.

The structure of budget revenues of the Republic of Crimea includes: uncompensated receipts -104.9 billion rubles, or $68.4 \%$; tax and non-tax revenues -48.2 billion rubles, or $31.6 \%$ (Figure 1).

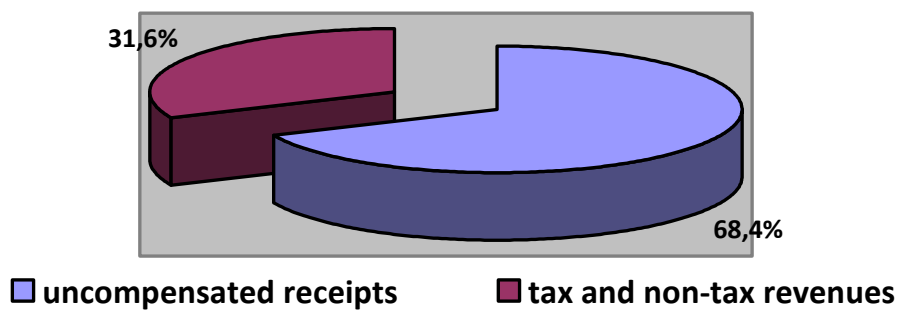

Fig. 1. Structure of budget revenues of the Republic of Crimea in 2021 [4].

The financial system of the region should also include household finances. For a highly subsidized region, such as the Republic of Crimea, it is important to ensure the growth of household incomes by increasing the efficiency of the self-employed population.

The support for small and medium-sized businesses, the development of production and an increase of the jobs number will create preconditions for increasing the revenue side of the budget, since in the structure of tax revenues of the budget of the Republic of Crimea, the main amount of revenues falls on 5 main sources: personal income tax $-42.7 \%$, tax on the profits of organizations $-15.1 \%$, excise tax $-20 \%$, the tax levied on organizations which apply the simplified taxation system $-6.6 \%$, tax on the property of organizations $7.1 \%$ (Figure 2). 


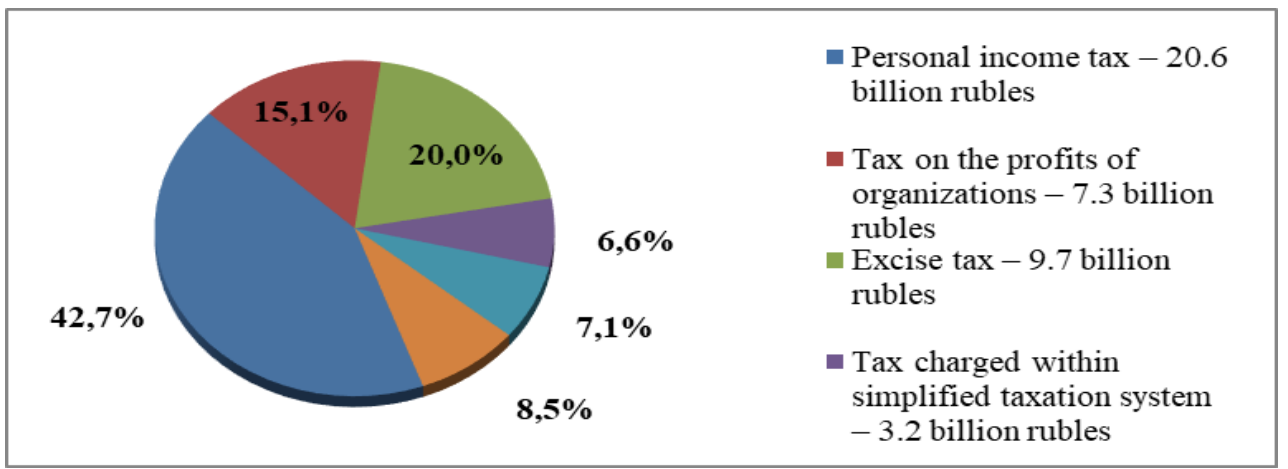

Fig. 2. Structure of tax and non-tax revenues of the budget of the Republic of Crimea in 2021 [5]

Analysis of tax revenues in the industry breakdown showed that the main budgetforming fields are manufacturing (24.08\%), as well as wholesale and retail trade, maintenance and repair of motor and other vehicles (16.12\% and $16.69 \%$, respectively). The contribution of other industries is less significant: transport and communications, public administration and military security, compulsory social security; production and distribution of electricity, gas and water.

Prospective forecasting of budget expenditures is an important tool for state regulation of economic and social processes, since it substantiates the directions for the use of budget funds in the future, taking into account certain goals and priorities of the socio-economic development of the state in the medium and long term (Figure 3).

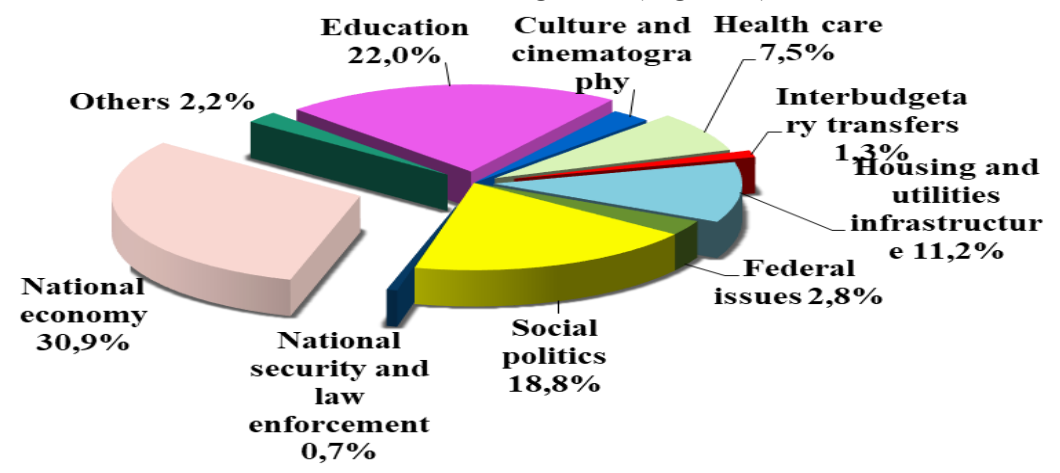

Fig. 3. Main directions of budget expenditures of the Republic of Crimea in 2021 by functional structure, \% [5]

Thus, having analyzed the structure of the budget of the Republic of Crimea, we can conclude that the budgetary policy is aimed at fulfilling the national development goals until 2024, at increasing the level and quality of life of the population, modernizing the infrastructure, economy and public administration, and repairing the public finances of the Republic of Crimea. At the same time, the budget of the Republic of Crimea is subsidized by $70 \%$ and, in our opinion, it will not be possible to achieve a significant reduction of this level soon. To reduce the subsidization of the budget, a significant economic growth and an increase in the volume of private investment are required.

Tax policy is an integral part of the country's socio-economic policy, which is focused on developing a tax system that will stimulate the accumulation and rational use of the state's national wealth, and thereby ensures the socio-economic development of society. The strategy focused on the economic growth of the region is aimed at the maximum tax support for competitive business, ensures the investment process of the region. 
In this regard, measures to attract financial resources for investment in the regional economy include: concessional lending to organizations that produce products which are innovative and strategically important for the region; creating a favourable investment climate in the region and ensuring the effectiveness of investments; introduction of tax holidays; investment in the continuous development of the labour potential of the region, etc.

The primary task of the tax policy of the Republic of Crimea is to take measures and elaborate actions on mobilization of taxes and fees, and repayment of tax arrears to replenish the revenue side of budgets [6].

In general, the regional tax policy of the Republic of Crimea is aimed at maintaining the balance of the consolidated budget by obtaining the required volume of budget revenues; support of investment activity of economic entities operating in the territory of the Republic of Crimea; improving the methods of tax administration and increasing the responsibility of the chief administrators of revenues for the fulfilment of the planned indicators of the flow of revenue in the consolidated budget of the Republic of Crimea.

The main priorities of the tax policy of the Republic of Crimea are the creation of favourable conditions for intense financial and economic activity of economic entities, ensuring the growth of the revenue side of the consolidated budget of the Republic of Crimea for its balance, certainty of the conditions for doing business and the investment attractiveness of the region. The tax policy of the Republic of Crimea is aimed at:

- development of small and medium-sized businesses;

- stimulating investment activity in the form of providing tax incentives and preferences to members of the Free Economic Zone;

- provision of investment tax deduction in respect of expenses of payers of corporate income tax;

- establishment of a single date for determining the tax base for property tax of individuals based on the cadastral value of taxable items;

- establishment of a unified procedure for determining the base for property tax;

- increase in the tax rate on property of organizations to $1.5 \%$;

- introduction of a tax on professional income for self-employed citizens on the territory of the Republic of Crimea ;

- formation and maintenance of a list of tax relief schemes (tax expenses).

Thus, we can conclude that the tax policy of the Republic of Crimea is effective and contributes to the development of the region's economy.

In order to improve the efficiency of the tax system, many states have resorted to lowering tax rates. A well-founded tax reduction definitely leads to an increase in household spending on the purchase of goods and services, the population's paying capacity, an increase in producers' income, an increase in investment, which undoubtedly stimulate the growth of the gross domestic product and ultimately lead to an increase in the volume of tax revenues to the budget.

In the Russian tax system, indirect taxes, which are easier to administer, prevail. However, indirect taxes do not stimulate production and are inflationary, since they are included in prices and are borne by the final consumer. In developed countries, the main budget-forming taxes in the structure of the tax system (60-70\%) are direct taxes: income tax, personal income tax, property taxes, which are paid on the income and property of taxpayers and are not passed on to the consumer. Undoubtedly, direct taxes are labor intensive and difficult to administer, but they are more results-oriented.

Thus, the priority direction of reforming the tax system in Russia, in our opinion, is to reduce the rates of indirect taxes and increase the rates of direct taxes by establishing a progressive scale of personal income tax, introducing a tax on property of individuals (for the Republic of Crimea), resort tax, etc. 
In our opinion, the primary tasks of the tax policy of the Republic of Crimea are to overcome the economic downturn amid the spread of a new coronavirus infection, to take anti-crisis measures during the pandemic, and to timely and fully fulfill social obligations to the population [7].

The directions of improving the tax policy of the Republic of Crimea for 2021-2025 include: the implementation of measures aimed at the development of individual, small and medium-sized businesses; strengthening the tax potential of the Republic of Crimea; implementation of measures to assess the volume and effectiveness of tax expenditures in the republic; strengthening budgets of urban districts and municipal areas, expanding their own revenue base by transferring part of the deductions from the budget of the Republic of Crimea. Directions for improving the tax policy of the Republic of Crimea for 2021-2025 are presented in Figure 4.

Directions for improving the tax policy of the Republic of Crimea for $2021-2025$

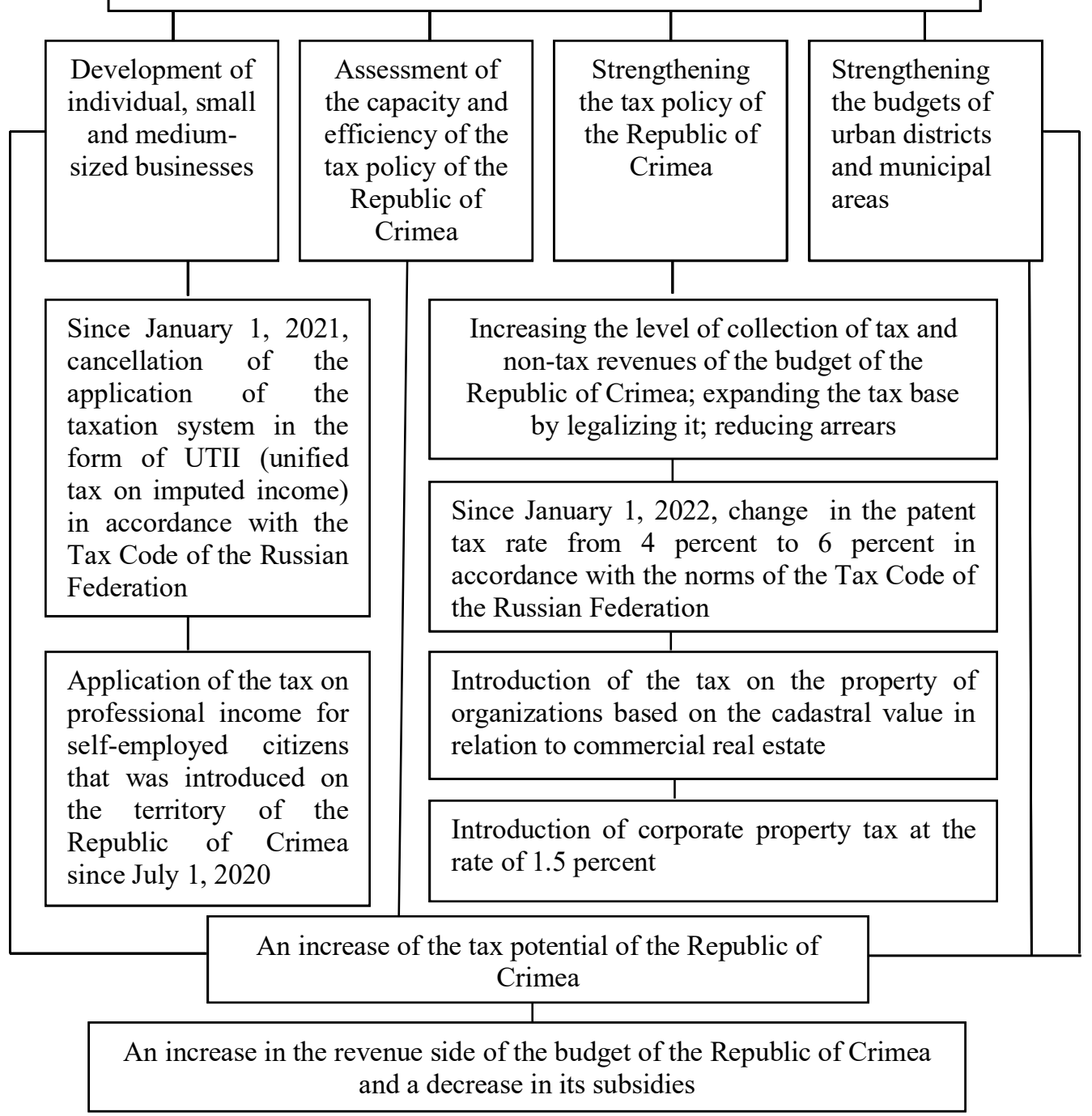

Fig.4. Directions for improving the tax policy of the Republic of Crimea in 2021-2025 


\section{Conclusions}

Thus, we can conclude that the comprehensive implementation of the proposed measures will make it possible to solve the key problems of the formation and modernization of the tax system, and to form an effective tax policy of the Republic of Crimea.

In our opinion, improving the regional tax policy is also possible through the implementation of the following measures aimed at developing the regional economy and improving the budgetary policy:

- formation of a scheme for the rational distribution of the gross regional product in accordance with the regional development strategy;

- creation of favorable conditions for the development of the real sector of the economy, assistance in activating the investment process; creating incentives for the development of small and medium-sized businesses;

- creation a favorable investment climate in the region and ensuring the efficiency of investments; introduction of tax holidays, etc.

- attracting financial resources for investment in the regional economy through concessional lending to organizations that produce strategically important and innovative products; targeted budget lending to priority sectors and industries;

- drawing up long-term regional programs of socio-economic development, providing them with budgetary resources;

- allocation of budgetary resources for the continuous development of labor potential;

- development of an effective system for assessing budgetary risks and budgetary obligations, as well as the effectiveness of the use of budgetary funds, etc.

The implementation of these measures, in our opinion, will help to increase the efficiency of regional tax policy and to achieve the priority tasks of the socio-economic development of the region. At the same time, the financial needs of the state should not infringe on the interests of taxpayers and slow down expanded reproduction. The implementation of large investment projects in the region, expansion of transport accessibility, improvement of infrastructure will contribute to sustainable economic development and enhance the tax potential of the region by creating new high-tech industries and jobs, and increasing the income of legal entities and individuals. This will allow the Republic of Crimea to increase the share of its own sources of budget replenishment and reduce subsidies by reducing interbudgetary transfers from the federal budget.

\section{References}

1. S. I. Chuzhmarova. RE. 19 (2013)

2. M. M. Levkevich, Yu. N. Pavlenko. Siberian Financial School, 3 (110) (2015).

3. T. V. Bushinskaya. Bulletin of Tula State University. Economic and legal sciences, 1 (2008).

4. Law of the Republic of Crimea of December 22, 2020 No. 139-zrk / 2020 "On the budget of the Republic of Crimea for 2021 and for the planning period of 2022 and 2023" [Electronic resource] // Open budget of the Republic of Crimea. - Access mode: https://budget.rk.ifinmon.ru/byudzhet-dlya-grazhdan/byudzhet-respublikikrym/osnovnye-kharakteristiki-byudzheta-respubliki-krym

5. The main characteristics of the budget of the Republic of Crimea [Electronic resource] // Open budget of the Republic of Crimea - Access mode: http://budget.rk.ifinmon.ru/byudzhet-dlya-grazhdan/byudzhet-respublikikrym/osnovnye-kharakteristiki-byudzheta-respubliki-krym. 
6. S.Vyvdyuk, T.N. Kadzhametova. Collection of scientific works "Modern management and administration: trends and development prospects", (2019).

7. T.N. Kadzhametova, A.R. Akhtemova. Scientific Notes of Crimean Engineering and Pedagogy University, 1 (71) (2021). 